\title{
Personality Change, CTCAE
}

National Cancer Institute

\section{Source}

National Cancer Institute. Personality Change, CTCAE. NCI Thesaurus. Code C143754.

A disorder characterized by a conspicuous change in a person's behavior and thinking. 